\title{
A millimeter-wave 6-bit digital attenuator with high accuracy and low insertion loss
}

\author{
Bo Zhanga) and Jing Zhao \\ ASIC Design Center, Xi'an University of Posts and Telecommunications, \\ West Changan Street, Xi'an 710121, China \\ a)bozhang910@gmail.com
}

\begin{abstract}
A millimetre-wave 6-bit attenuator with high accuracy and low insertion loss by $0.15 \mu \mathrm{m}$ GaAs PHEMT process is presented. A proposed structure is adopted to enhance the attenuation accuracy. A cascade structure is proposed to enhance isolation and compensate the insertion loss. The measurement results show that it has $0.5 \mathrm{~dB}$ resolution and $31.5 \mathrm{~dB}$ attenuation rage while the return loss is better than $-10 \mathrm{~dB}$ for all states. The attenuation accuracy is better than $0.5 \mathrm{~dB}$ while the RMS attenuation error is less than $0.21 \mathrm{~dB}$. The insertion loss is less than $5.7 \mathrm{~dB}$ while the insertion phase shift is less than $-6.0^{\circ}$.
\end{abstract}

Keywords: attenuator, millimeter-wave, accuracy, insertion loss, PHEMT Classification: Microwave and millimeter-wave devices, circuits, and modules

\section{References}

[1] I. Ju, et al.: IEEE Microwave Conf. Euro. (2005) 4.

[2] N. Chen: MMWCST (2013) 440.

[3] Y. Zhang, et al.: IEICE Electron. Express 11 (2014) 20140394 (DOI: 10.1587/ elex.11.20140394).

[4] L. Zhao, et al.: IEEE APMC (2014) 1196.

[5] Y.-S. Dai, et al.: ICUWB (2010) 1 (DOI: 10.1109/ICUWB.2010.5614714).

[6] Y.-S. Dai, et al:: ICMMT (2012) 1.

[7] W. Ciccognani, et al.: Electron. Lett. 44 (2008) 743 (DOI: 10.1049/ el:20080987).

[8] H. Eom, et al.: Global Symposium on Millimeter Waves (2008) 101 (DOI: 10.1109/GSMM.2008.4534569).

[9] C. C. Su, et al.: IEEE Microw. Wireless Compon. Lett. 25 (2015) 124 (DOI: 10.1109/LMWC.2014.2382688).

[10] Y. Yuan, et al.: IEICE Electron. Express 13 (2016) 20160086 (DOI: $10.1587 /$ elex.13.20160086). 


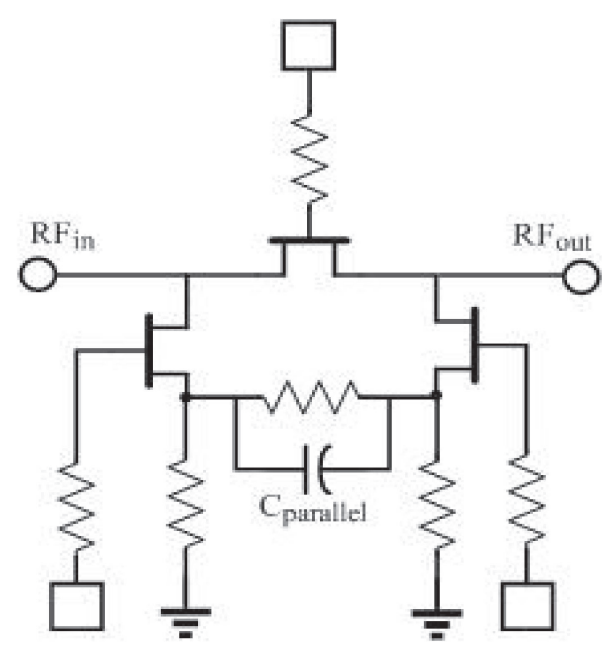

Fig. 1. Proposed $\pi$-type unit

\section{Introduction}

With the rapidly incensing demand of millimetre-wave technology, the digital controlling attenuator plays an more and more important in radar, communication, electronic equipments $[1,2,3]$. When the operation frequency reaches millimetrewave band, the attenuator with high accuracy and low insertion loss is difficult to realize, due to the low isolation, high substrate loss and the prominent parasitic parameter. The III-V compound semiconductors were generally utilized in attenuator design. However, with the increase of operation frequency, the high attenuation accuracy and low insertion loss are difficult to achieve at same time. In this letter, we present a Ka-band 6-bit digital attenuator. By an accuracy enhancement structure, the attenuation accuracy is better than $0.5 \mathrm{~dB}$ and the RMS attenuation is less than $0.21 \mathrm{~dB}$. Meanwhile a cascade structure is adopted for higher isolation and lower and insertion loss. The results show that a 6-bit digital attenuator in Kaband is achieve with $0.5 \mathrm{~dB}$ resolution and $31.5 \mathrm{~dB}$ dynamic attenuation range, while the insertion phase shift is less than $-6.0^{\circ}$. The whole chip size is $2.0 \mathrm{~mm} \times$ $1.0 \mathrm{~mm}$ with test pad.

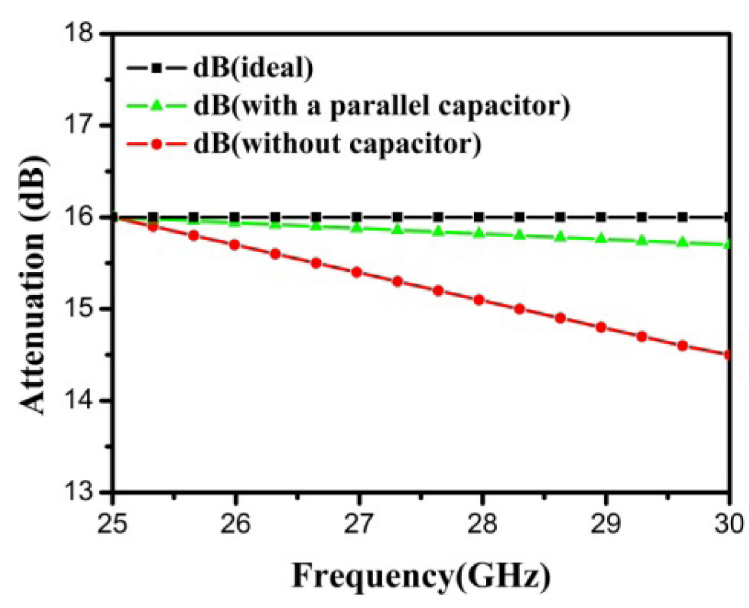

Fig. 2. Attenuation value versus frequency 


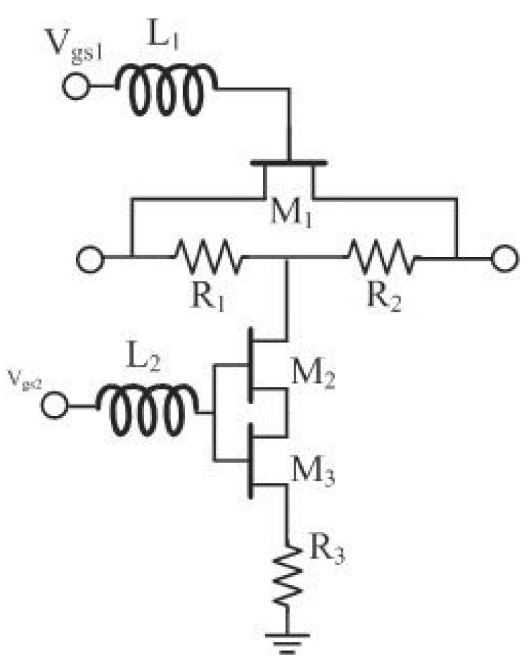

(a)

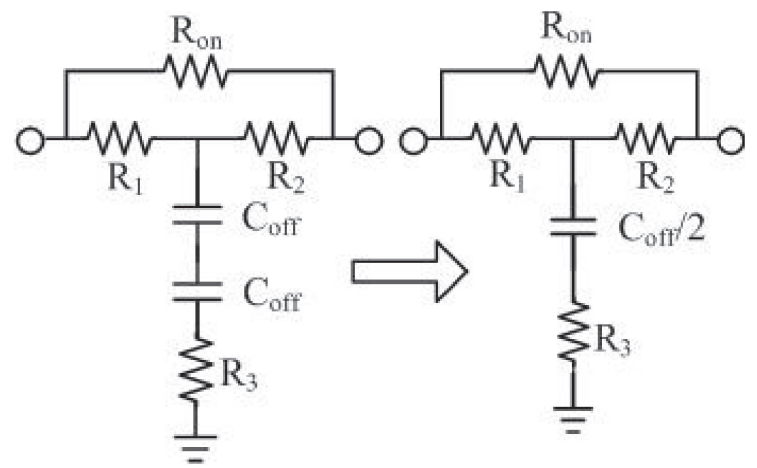

(b)

Fig. 3. Proposed cascade structure. a) Schematic of cascade structure; b) Equivalent circuit of cascade structure.

\section{Circuit design}

The whole circuit is composed by six main attenuation units, $0.5,1,2,4,8,16 \mathrm{~dB}$. Due to the damping resistance for $0.5 \mathrm{~dB}$ unit and $1 \mathrm{~dB}$ unit is small, T-type structure is selected, while the transmission line is used to instead of internal resistance. For $2 \mathrm{~dB}$ unit and $4 \mathrm{~dB}$ unit, T-type structure is also adopted for its small chip area. In order to achieve the good return loss and attenuation accuracy, $\pi$-type is used for $8 \mathrm{~dB}$ unit and $16 \mathrm{~dB}$ unit design. However, with the increase of operation frequency, the performance will be deteriorated dramatically by parasitic effects $[4,5,6,7]$.

Since the parasitic capacitance and shunt inductance limit the attenuation flatness in high frequency, the attenuation value will be decreased with the increase of operation frequency, especially for large attenuation unit. In order to enhance the accuracy and reduce the insertion loss, an improved structure with a parallel capacitor is proposed, as shown in Fig. 1. The parallel resistor and capacitor are used to compensate the attenuation fall by parasitic effect at high frequency. The broad band flat attenuation can be achieved by optimizing the value of parallel capacitor and resistor. Fig. 2 shows the simulation results of proposed structure for attenuation value versus frequency. 


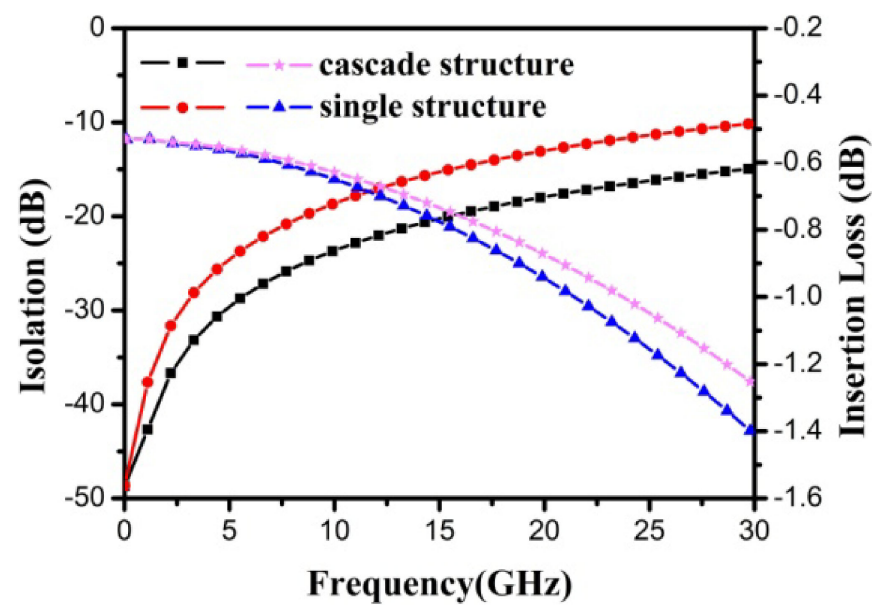

Fig. 4. Isolation and insertion loss of single and cascade structures.

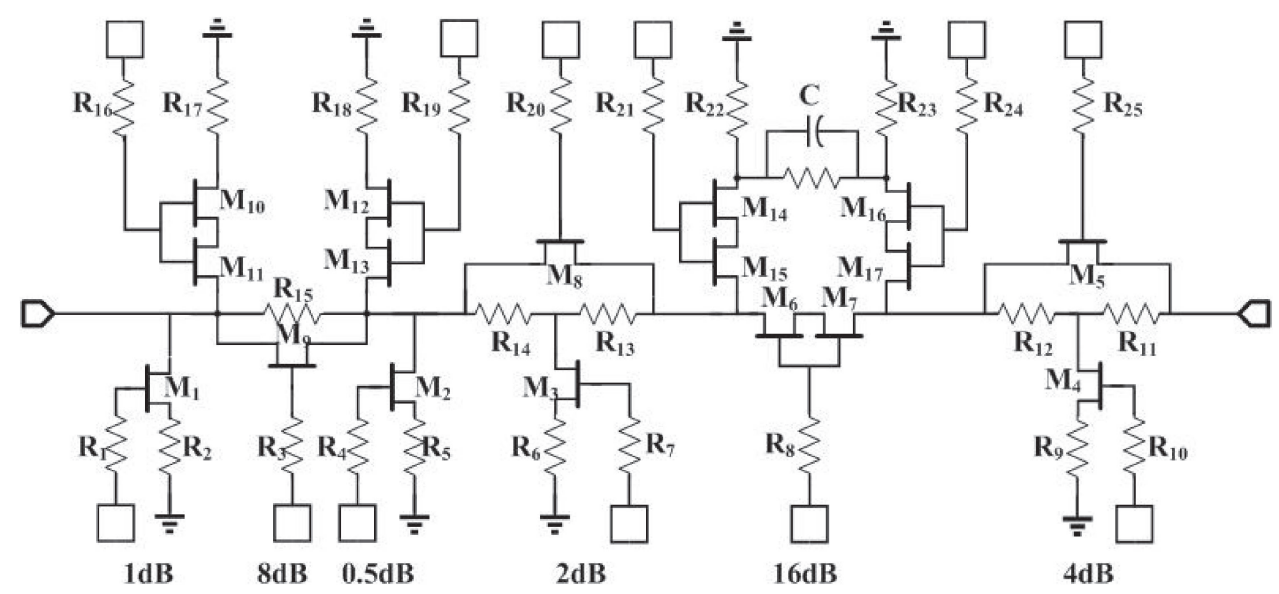

Fig. 5. Schematic of proposed attenuator

The whole circuit is composed by six units, the isolation of switch transistor dominates the leakage of the RF signal to undesirable channel and pass band ripple. However, the effect of turn-off capacitor and series resistor of transistor impact the isolation. Thus, the isolation of a single switch PHEMT is not enough for expected isolation, as well as the bandwidth is narrow relatively in fact [8]. In order to enhance the isolation, a high isolation cascade structure is proposed, as shown in

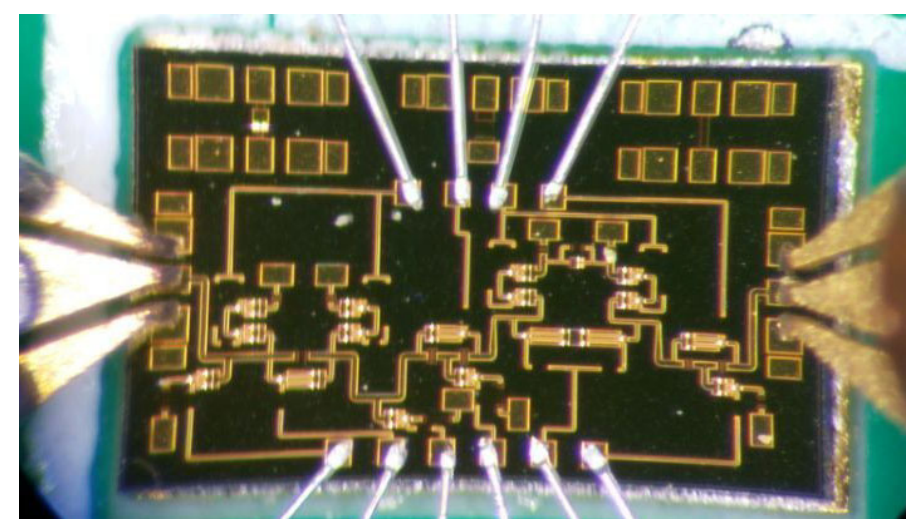

Fig. 6. Microphotography of proposed 


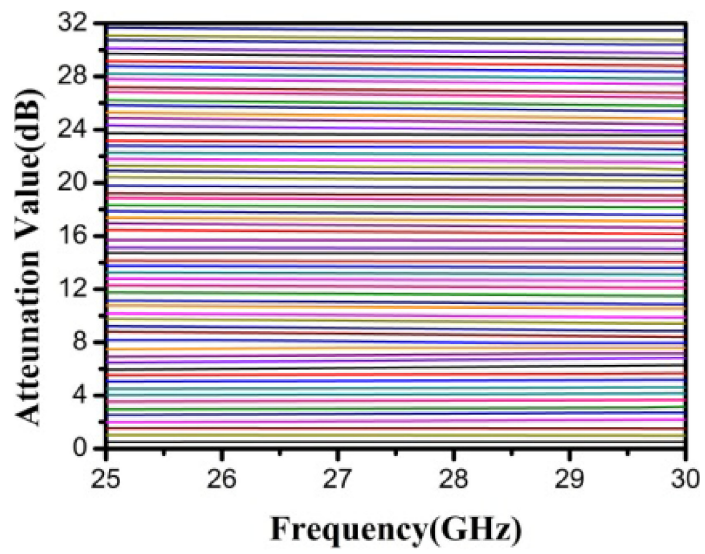

(a)

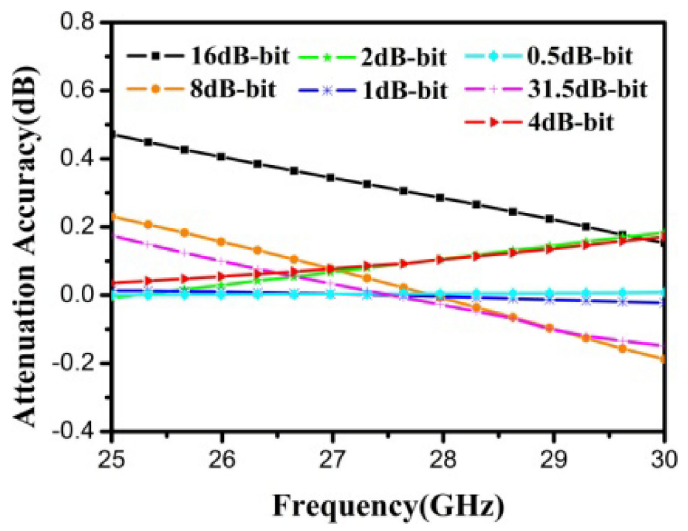

(b)

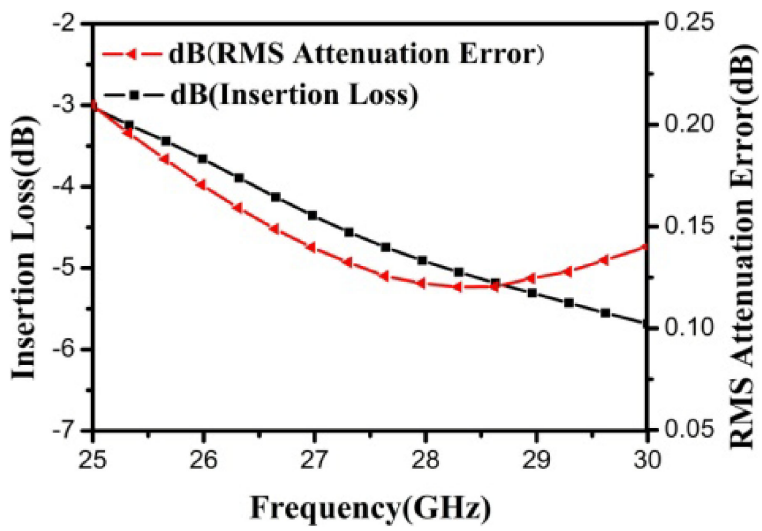

(c)

Fig. 7. Measurement results of proposed attenuator. a) All attenuation bits in $25-30 \mathrm{GHz}$; b) Attenuation accuracy in $25-30 \mathrm{GHz}$; c) RMS attenuation error and Insertion loss

Fig. 3(a). The equivalent circuit of proposed structure when transistor is tuned on or off is shown in Fig. 3(b). The signal leakage is mainly produced by the parasitic capacitance. In proposed structure, signal leakage is reduced due to the parasitic capacitance is halved. Therefore, the isolation of whole circuit is improved as well as the insertion loss in reference state is also reduced. The simulation results of isolation and insertion loss between traditional and proposed structure is shown in 
Table I. Benchmarking table of millimeter-wave attenuator.

\begin{tabular}{|c|c|c|c|c|c|}
\hline Parameter & Hittite & Tri-Quint & Ref. [1] & Ref. [2] & This work \\
\hline Process & $\begin{array}{c}0.15 \mu \mathrm{m} \\
\mathrm{GaAs}\end{array}$ & $\begin{array}{c}0.15 \mu \mathrm{m} \\
\mathrm{GaAs}\end{array}$ & $\begin{array}{c}0.15 \mu \mathrm{m} \\
\mathrm{GaAs}\end{array}$ & $\begin{array}{c}0.15 \mu \mathrm{m} \\
\mathrm{GaAs}\end{array}$ & $\begin{array}{l}0.15 \mu \mathrm{m} \\
\text { GaAs }\end{array}$ \\
\hline $\begin{array}{l}\text { Freq. } \\
(\mathrm{GHz})\end{array}$ & $26.5-33$ & $18-30$ & DC-40 & $19-23$ & $25-30$ \\
\hline $\begin{array}{l}\text { Step/Bit } \\
\text { (dB/bit) }\end{array}$ & $1 / 5$ & $0.5 / 5$ & $1 / 5$ & $0.5 / 6$ & $0.5 / 6$ \\
\hline $\begin{array}{l}\text { Att. Accuracy } \\
(\mathrm{dB})\end{array}$ & $< \pm 1$ & $< \pm 1.5$ & $<+1.3$ & $<+1.31$ & $<0.5$ \\
\hline $\begin{array}{l}\text { Insertion Loss } \\
(\mathrm{dB})\end{array}$ & $\leq-6.5$ & $\leq-4.2$ & $\leq-8$ & $\leq-3$ & $\leq-5.7$ \\
\hline $\begin{array}{l}\text { RMS Att. Error } \\
\text { (dB) }\end{array}$ & $\mathrm{N} / \mathrm{A}$ & 0.9 & $\mathrm{~N} / \mathrm{A}$ & $\mathrm{N} / \mathrm{A}$ & $<0.21$ \\
\hline $\begin{array}{c}\text { Return Loss } \\
(\mathrm{dB})\end{array}$ & $<-12$ & $<-9$ & $<-15$ & $<-11$ & $<-10$ \\
\hline $\begin{array}{c}\text { Insertion Phase } \\
\text { Shift } \\
\left({ }^{\circ}\right) \\
\end{array}$ & $\leq 80^{\circ}$ & $\leq 33^{\circ}$ & $\mathrm{N} / \mathrm{A}$ & $<-5.0^{\circ}$ & $<-6.0^{\circ}$ \\
\hline $\begin{array}{c}\text { Chip Size } \\
\left(\mathrm{mm}^{2}\right)\end{array}$ & 2.4 & 0.94 & 4.5 & 6 & 2.0 \\
\hline
\end{tabular}

circuit, the attenuation unit with better VSWR is placed at the two sides of the whole circuit, while the worse ones are placed in the middle. Fig. 5 shows the schematic of the whole proposed attenuator.

\section{Results}

The proposed Ka-band 6-bit attenuator is fabricated in $0.15-\mu \mathrm{m}$ GaAs process. The whole chip size is $2.0 \mathrm{~mm} \times 1.0 \mathrm{~mm}$, which includes test pad. The measurement is de-embedded by using a calibration substrate. The microphotography of die is shown in Fig. 6. The measured result is shown in Fig. 7. The attenuator achieves less than $0.21 \mathrm{~dB}$ RMS attenuation error, while the return loss is better than $-10 \mathrm{~dB}$. The comparison of previous work and this work is shown in Table I. This work demonstrated highest attenuation accuracy with lower insertion loss.

\section{Conclusion}

A Ka-band 6-bit digital attenuator by $0.15 \mu \mathrm{m}$ GaAs process is reported. The improved attenuation structure with capacitor in parallel and a high isolation cascade structure are employed. The measurement results show the digital attenuator has $0.5 \mathrm{~dB}$ resolution and $31.5 \mathrm{~dB}$ dynamic attenuation range, while the return loss is better than $-10 \mathrm{~dB}$ for all states. The attenuation accuracy is better than $0.5 \mathrm{~dB}$ while the RMS attenuation error is less than $0.21 \mathrm{~dB}$; The insertion loss is less than $5.7 \mathrm{~dB}$ while the insertion phase shift is less than $-6.0^{\circ}$. The proposed method and structure make the attenuator obtain excellent attenuation accuracy and insertion loss. 


\section{Acknowledgments}

This work is supported by National Natural Science Foundation of China

(Grant No. 61201044), New Star Team of Xi'an University of Posts \& Telecommunications. 